\title{
Kangaroo Mother Care at Low Birth Weight
}

\author{
Maryanah $^{1}$, Sri Sukamti ${ }^{2}$ Juli Oktalia ${ }^{3}$, Novita Rina Antarsih ${ }^{4}$, Indra Supradewi ${ }^{5}$, Aticeh ${ }^{6}$ \\ 1,2,3,4,5,6 Midwifery department of Health Polytecnic of Ministry of Health Jakarta III \\ Jl. Arteri JORR Jatiwarna Pondok Melati Bekasi Indonesia \\ Corresponding author's email: maryanah559 [AT] gmail.com
}

\begin{abstract}
Kangaroo Care Method is a treatment given to babies with Low Birth Weight (LBW) as an alternative to an incubator. This method uses direct contact between the mother's skin and baby's skin or skin to skin contact. The kangaroo method not only replaces the care of the incubator but also provides benefits that cannot be provided by the incubator. Increasing the baby's body temperature, stabilizing heart rate and breathing, and increasing milk production, decreases the incidence of infection in infants. The purpose of this study was to determine the effectiveness of the use of the kangaroo method on LBW in Karawang Hospital. The cross-sectional research method uses secondary data through treatment records in the medical record. The study sample was $106 \mathrm{LBW}$ infants treated at Karawang Hospital in the 2018 period. Analysts used average difference test data to see the effectiveness of using the kangaroo method in increasing infant weight. Results: There is an effect of the use of the kangaroo method to increase the baby's weight P-value 0,0001. Recommendation: It is expected that the use of the kangaroo method on $L B W$ can be made into policy at the hospital with the support of health workers and facilities so that families can implement kangaroo mother care (KMC) in full.
\end{abstract}

Keywords- KMC, LBW

\section{INTRODUCTION}

Low birth weight (LBW) is one of the causes of death of newborn babies because it is vulnerable to risks that adversely affect the health of babies both direct and long-term impacts.[1, 2, 3]. The World Health Organization (WHO, 2016) defines LBW as a newborn who weighs less than 2500 grams. According to the WHO data report (2014), globally the prevalence of LBW is estimated from 20 million babies born there are 15-20\% who experience LBW every year. The highest prevalence of low birth weight is found in the regional region, namely South Asia (28\%), followed by subSaharan Africa (13\%) and Latin America (9\%) [4]. LBW maintenance still prioritizes the use of incubators that have weaknesses, namely limited numbers, expensive incubator maintenance and requires skilled personnel to operate it [5]. Also, it causes the absence of direct skin contact that is very much needed between mother and baby for the growth and development of the baby to be blocked [6]. The impact of LBW treatments is lacking, causing hypothermia and nosocomial infections $[5,6,7]$

The effectiveness of the implementation of the kangaroo method has a good effect on the care of premature babies. The position in the kangaroo method is the baby placed on the mother's chest becomes an effective source of heat for the baby and makes the mother play an active role in caring for her baby [1]. A comparative study of care between using an incubator and the FMD method reports that infants with FMD have greater weight gain than infants with incubator care and shorter hospital stays. During interventions, babies have better survival because no infant mortality is found due to premature [8]. Also, the baby's body temperature can be maintained at the time of bonding [9].

\section{METHODS}

The cross-sectional research method uses secondary data through treatment records in the medical record. The research sample was $106 \mathrm{LBW}$ infants treated at Karawang Hospital in 2018. Analysts used a different test to see the effectiveness of using the kangaroo method in increasing infant weight. 


\section{RESULTS}

Table 1: LBW Characteristics of Karawang Hospital in $2018(\mathrm{n}=106)$

\begin{tabular}{lcc}
\hline Variables & $\mathbf{N}$ & $\mathbf{\%}$ \\
\hline Age & & \\
$<20$ and $>35$ & 26 & 24.5 \\
$20-35$ & 80 & 75.5 \\
Education & & \\
SD & 44 & 41.5 \\
SMP & 39 & 36.8 \\
SMA & 21 & 19.8 \\
D3 & 2 & 1.9 \\
Gestation & & \\
Preterm & 93 & 87.7 \\
Aterm & 13 & 12.3 \\
Parity & & \\
1 & 48 & 45.3 \\
2 & 28 & 26.4 \\
3 & 15 & 14.2 \\
4 & 10 & 9.4 \\
5 & 4 & 3.8 \\
6 & 1 & 0.9 \\
Delivery & & \\
SC & 60 & 56.6 \\
Spontaneous & 46 & 43.4 \\
Status in Birth & & \\
Asphyxia & 75 & 70.8 \\
Normal & 31 & 29.2 \\
Nutrition & & \\
Breast Milk & 59 & 55.7 \\
Formula & 22 & 20.8 \\
Breast milk \& Formula & 25 & 23.6 \\
\hline
\end{tabular}

Based on table 1 it can be seen that the incidence of LBW in Karawang hospitals is majority born to mothers of healthy reproductive age (75.5\%) with majority education (41.5\%) and junior high schools (36.8), LBW in Karawang the majority of hospitals is pure premature which can be seen from the gestational age of Preterm by $87.7 \%$ and almost half are the first child off at $45.3 \%$, the delivery process is more than half with cesarean section surgery $56.6 \%$ and the majority experience asphyxia at birth by $70.8 \%$, while the nutrition received by the baby after birth is $55.7 \%$ breast milk, the remaining $20.8 \%$ formula is a mixture of breast milk with a formula of $23.6 \%$.

From a sample of $106 \mathrm{LBW}$ from medical record data, it was found that several infants whose KMC was given no more than 5 days so that the data that can be analyzed until the fifth day were $65 \mathrm{LBW}$. In this study can not present the full or partial KMC group and can not present LBW without KMC because of limited data in hospital medical records that have not been connected to all documents and have not used a computerized system.

Data on infant weight at birth, the first day until the fifth day are all normally distributed so that analysis can be done with the dependent T-test. The results are as follows;

Table 2: The Low Birth Weight Distribution in Karawang Hospital in 2018

\begin{tabular}{lccccc}
\hline \multicolumn{1}{c}{ Variable } & N & Mean & SD & Min & Max \\
\hline Birth Weight & 106 & 1896.62 & 337.728 & 1090 & 2560 \\
Birth weight day 1 & 106 & 1846.61 & 360.678 & 1070 & 1847 \\
Birth weight day 2 & 104 & 1830.99 & 368.004 & 1080 & 26.95 \\
Birth weight day 3 & 83 & 1734.05 & 332.414 & 1110 & 2500 \\
Birth weight day 4 & 71 & 1697.23 & 312.358 & 1110 & 2550 \\
Birth weight day 5 & 65 & 1672.49 & 312.840 & 1085 & 2580 \\
\hline
\end{tabular}

Based on table 2, the minimum and maximum values of a baby's body get bigger with SD getting smaller which shows the increase in baby's weight with smaller data variations, but the number of subjects with data that complements the use of KMC is getting smaller. On day 3 only 83 babies, day 4 there were 71 babies and day 5 there were 65 babies. 
Table 3: Distribution of mean differences weight of infants by weight at birth and after KMC in Karawang Hospital 2018

\begin{tabular}{ccccccc}
\hline Variable & N & $\begin{array}{c}\text { Mean } \\
\text { Diff }\end{array}$ & SD & SE & $\begin{array}{c}\text { P } \\
\text { Value }\end{array}$ & 95\% CI Mean Diff \\
\hline Birth weight day 1 & 106 & 50.0094 & 96.9303 & 9.4147 & 0.000 & $31.3418-68.6670$ \\
Birth weight day 2 & 104 & 61.9135 & 137.5779 & 13.4906 & 0.000 & $35.1580-88.6689$ \\
Birth weight day 3 & 83 & 94.3494 & 138.1918 & 15.1685 & 0.000 & $64.1744-124.5244$ \\
Birth weight day 4 & 71 & 116.8873 & 138.2531 & 16.4076 & 0.000 & $84.1633-149.6113$ \\
Birth weight day 5 & 65 & 117.5385 & 140.9440 & 17.4820 & 0.000 & $82.6142-152.4627$ \\
\hline
\end{tabular}

Based on table 3 it was found that the difference in average weight of the baby at birth with after the use of KMC on the first day was 50 grams, the second day weighed 61.9 grams, the third day weighed 94.34 grams, the 4th day amounted to 116.88 grams and the 5 th day was 117.53 grams.

The analysis results obtained p-value 0.001 so that it was concluded that there were differences in the average weight of the baby at birth with each set using the kangaroo method on the first day. Second, third, fourth and fifth.

From the mean difference, it can be seen that the increase in baby's weight is increasing with more days of KMC use.

\section{DISCUSSION}

\subsection{An overview of the demographic characteristics of the respondents}

The results showed the characteristics of respondents according to the chart is that most respondents were born by mothers of healthy reproductive age $(75.5 \%)$. This is different from previous researchers who mentioned the significant risk factors of low birth weight were older age (35 years and above) other researchers stated that LBW was born to adolescent (and not adult) mothers [10,11]. This is reinforced by other researchers who report that the prevalence of LBW when the mother is 40-54 years of age is double that when she is 20-24 years of age[12]. According to researchers, this is likely due to the many healthy reproductive-age mothers who have low socioeconomic status at Karawang Hospital.

The majority of elementary school education $(41.5 \%)$ and junior high school (36.8), this is likely due to the high incidence of early marriage in Karawang and the lack of maternal knowledge about the importance of regular ANC. This is in line with previous studies which reported that LBW mostly occurs in mothers with Low education / primary education [13, 14] so it is recommended to improve maternal education [15]. Other researchers report that women with less than a high school diploma have $36 \%$ greater chance of having an LBW infant than the reference group of women with a bachelor's degree or higher [12]

LBW in the majority of Karawang Hospital is pure premature which can be seen from the gestational age of Preterm by $87.7 \%$. This is likely due to the poor nutritional status of pregnant women. This is in line with previous research which reported that the neonates who were delivered before 37 weeks of the gestational age were 18 times more likely to be LBW compared to the neonates delivered at or above 37 weeks of gestation [16].

Almost half are the first child which is $45.3 \%$. According to researchers, this is likely due to a lack of maternal knowledge about the importance of regular ANC. This is supported by previous studies which reported that LBW is associated with primiparity [17]. while other researchers mention the significant risk factors of low birth weight parity of 4 and above [10]. Other studies have shown that primigravida was found to be significantly associated with LBW $[10,18]$.

The delivery process was more than half with $56.6 \%$ of cesarean section surgery. According to researchers, this is probably due to prevent the occurrence of prolonged labor because LBW is at risk of asphyxia because the body is not yet mature, especially the respiratory system. This is in line with previous research which reported that more than $50 \%$ of preterm births are spontaneous [19]. Delivery using lower segment caesarian section (LSCS) was found to have more risk in developing LBW compared to infants delivered via vaginal delivery [20].

The majority experienced asphyxia at birth by $70.8 \%$. This is supported by previous research which reported that low birth weight was significantly associated with perinatal asphyxia [21] According to researchers, this might be due to the immature respiratory system in LBW infants.

while the nutrition received by the baby after birth is $55.7 \%$ breast milk, the remaining $20.8 \%$ formula is a mixture of breast milk with a formula of $23.6 \%$. The provision of nutrition for babies may be adjusted to the condition of the mother, both breast milk production from the mother and the mother's disease. However, other studies suggest that LBW 
infants fed breast milk had better growth z-scores and lower SGA status at discharge compared with those predominately fed preterm formulas [22]

\subsection{Low Birth Weight Distribution}

There is an increase in infant weight with a smaller variation of data, but the number of subjects with complete data using KMC is getting smaller. On day 3 only 83 babies, day 4 there were 71 babies and day 5 there were 65 babies. This is likely due to the baby being healthy and discharged and not knowing the implementation of the KMC at home/community. This is supported by the theory which states that KMC until 28 days of age or until the baby no longer wants to stay in the KMC position [23].

\subsection{Distribution of differences in average infant weight according to weight at birth and after KMC}

The increase in baby's weight is increasing with more and more days of KMC use. This is supported by other studies reporting that KMC improved growth in LBW babies' high risk, significant improvement in all anthropometric parameters in babies [24,25] This is probably due to the baby's body temperature becoming stable and organ function can develop quickly so that the baby experiences an increase in growth and progressive development.

\section{CONCLUSION}

Based on the results of the study it can be concluded that the use of KMC is very effective for increasing the weight of the baby so that it is expected to continue, especially in infants with LBW in Karawang hospital.

Recommendations for further research examines the socioeconomic status of the mother, age at marriage, frequency and quality of the ANC, and nutritional status of the mother.

\section{REFERENCES}

[1] Dirjen Binkesmas. Modul manjemen bayi berat lahir rendah (BBLR) untuk bidan di desa. Depkes; 2008.

[2] Dahlui, Mazna, etc. Risk Factors for Low Birth Weight In Nigeria: Evidence From The 2013 Nigeria Demographic And Health Survey. Global Health Action. 2016;

[3] WHO. Factsheet Newborns: Reducing Mortality. In Geneva; 2016.

[4] UNICEF, WHO. Low Birth Weight, Country, Regional And Global Estimates. In 2004.

[5] Department of Reproductive Health and Research. Kangaroo Mother Care a Practical Guide. 1st ed. Geneva: WHO; 2003.

[6] Depkes. Pedoman Pelayanan Kesehatan Bayi Berat Lahir Rendah (BBLR) dengan Perawatan Metode Kanguru di Rumah Sakit dan Jejaringnya. 2009.

[7] Imaniar, E, Apriliana, E, Rukmono, P. Kualitas Mikrobiologi Udara di Inkubator Unit Perinatologi RSUD Dr. Abdul Moeloek Bandar Lampung. MAJORITY (Medical Journal of Lampung University).

[8] Kambarami, R. A, Chidede.O, Kowo, D., T. Kangaroo Care versus Incubator Care In The Management of Well Preterm Infants-A Pilot Study. Annals of Tropical Prediatrics. 1998;(18):81-6.

[9] MD. Santhi, Kokilavani. Effect of Kangaroo Mother Care on Neonatal Temperature and Weight among Newborns. Nursing Journal of India. 2013;87-90.

[10] Yadav H, Lee N. Maternal Factors in Predicting Low Birth Weight Babies. Med J Malaysia. 2013;68(1):44-7.

[11] Vaske J, Newsome J, Boisvert D, Piquero A, Paradise A, Buka S. The impact of low birth weight and maternal age on adulthood offending. Journal of Criminal Justice. 2015;43(1):49-56.

[12] Ratnasiri A, Parry S, Arief V, DeLacy L, Halliday L, DiLibero R, et al. Recent trends, risk factors, and disparities in low birth weight in California, 2005-2014: a retrospective study. Maternal Health, Neonatology, and Perinatology. 2018;4(15):1-13.

[13] El-Moselhy E, Nada I, Khalifa H, Mohammad K. Low Birth Weights: I- Maternal Risk Factors - A Hospital- Based Study In Cairo City, Egypt. The Egyptian Journal of Hospital Medicine. 2012;14:555- 572.

[14] Bian Y, Zhang Z, Liu Q, Wu D, Wang S. Maternal risk factors for low birth weight for term births in a developed region in China: a hospital-based study of 55,633 pregnancies. The Journal of Biomedical Research. 2013;27(1):14-22.

[15] Bhaskar S, Deo K, Neupane U, Bhaskar S, Yadav B, Pokharel H, et al. A Case Control Study on Risk Factors Associated with Low Birth Weight Babies in Eastern Nepal. International Journal of Pediatrics. 2015;

[16] Sema A, Tesfaye F, Belay Y, Amsalu B, Bekele D, Desalew A. Associated Factors with Low Birth Weight in Dire Dawa City, Eastern Ethiopia: A Cross-Sectional Study. BioMed Research International. 2019;1-8.

[17] Khan A, Nasrullah F, Jaleel R. Frequency and risk factors of low birth weight in term pregnancy. Pak J Med Sci. 2016;32(1):138-42.

[18] Davoudi N, Khezri M, Asgarpour M, Khatami S, Hoseinpour M, Azarian A. Prevalence and Related Factors of Low Birth Weight in Mashhad. Iranian Journal of Neonatology. 2012;(3):69-76.

[19] Murad M, Arbab M, Khan M, Abdullah S, Ali M, Tareen S, et al. Study of Factors Affecting and Causing Preterm Birth. Journal of Entomology and Zoology Studies. 2017;5(2):406-9. 
[20] Sutan R, Mohtar M, Mahat AN, Tami A. Determinant of Low Birth Weight Infants: A Matched Case Control Study. Open Journal of Preventive Medicine. 2014;(4):91-9.

[21] Alemu A, Melaku G, Abera G, Damte A. Prevalence and associated factors of perinatal asphyxia among newborns in Dilla University referral hospital, Southern Ethiopia- 2017. Pediatric Health, Medicine and Therapeutics. 2019;(10):69-74.

[22] Lok K, Chau P, Fan H, Chan K, Chan B, Fung G, et al. Increase in Weight in Low Birth Weight and Very Low Birth Weight Infants Fed Fortified Breast Milk versus Formula Milk: A Retrospective Cohort Study. Nutrients. 2017;9(520):1-9.

[23] Mazumder S, Taneja S, Dalpath S, Gupta R, Dube B, Sinha B, et al. Impact of community-initiated Kangaroo Mother Care on survival of low birth weight infants: study protocol for a randomized controlled trial. Trials. 2017;18(262):1-10.

[24] Udani R, R A, Kabra N, Navati R. Impact of Duration of Kangaroo Mother Care on Growth in High Risk Preterm and Low Birth Weight Infants. Journal of Neonatology. 2013;27(3):1-9.

[25] Swarnkar K, Vagha J. Effect of Kangaroo Mother Care on Growth and Morbidity Pattern in Low Birth Weight Infants. JKIMSU. 2016;5(1):91-9. 